\title{
Sourcing Strategy and Supply Chain Risk Management in the Healthcare Sector: A Case Study of Malawi's Public Healthcare Delivery Supply Chain
}

\author{
Kizito Elijah Kanyoma ${ }^{1}$, James Kamwachale Khomba ${ }^{2}$, Eric James Sankhulani ${ }^{2}$ \& Rabiya Hanif ${ }^{3}$ \\ ${ }^{1}$ Department of Business Administration, University of Malawi, Malawi \\ ${ }^{2}$ Department of Management Studies, University of Malawi, Malawi \\ ${ }^{3}$ Department of Accountancy, University of Malawi, Malawi \\ Correspondence: Kizito Elijah Kanyoma (MSc. SCM. Bolton - UK), Lecturer, Department of Business \\ Administration, University of Malawi, Private Bag 303, Blantyre 3, Malawi. E-mail: kkanyoma@poly.ac.mw, \\ kkanyoma@gmail.com
}

Received: March 23, 2013

Accepted: May 14, 2013

Online Published: August 1, 2013

doi:10.5430/jms.v4n3p16

URL: http://dx.doi.org/10.5430/jms.v4n3p16

\begin{abstract}
The study primarily investigated the role of single sourcing strategy in either exacerbating or mitigating persistent supply failure in Malawi's public healthcare delivery supply chain. It also investigated the role of the single supplier in recurrent drug stockouts in the country's public hospitals. The study was conducted at five public healthcare delivery centres in southern Malawi. Data was collected using two sets of self administered questionnaires to, hospital managers and procurement staff at participating hospitals. Follow up interview with randomly selected managers were also scheduled to complement the data from questionnaires. The study findings confirmed that single sourcing exacerbates the risk of supply failure, evidenced by persistent stockouts of drugs in hospitals that consequently put at risk lives of many patients who rely on the public healthcare system. Such stockouts had multiple effects on the public healthcare delivery supply chains ranging from death of patients, deterioration of medical conditions of patients, hospital overcrowding, to transfer of patients to other hospitals (mostly private). Failure by the government instituted single supplier namely the Central Medical Stores, to maintain an adequate inventory of drugs both in quantity and variety, was found to be the most important cause of stockouts. From the study, it has been shown that the single sourcing strategy exacerbated the risk of supply failure, and is therefore generally inappropriate for healthcare delivery systems. It is hoped that these findings will help policy makers in making the right procurement strategies and policies in order to enhance healthcare delivery.
\end{abstract}

Keywords: healthcare delivery, Malawi, procurement, single sourcing, sourcing strategy, supply chain risk management

\section{Introduction}

The importance of risk for supply chain management has become more apparent over the years and cannot be overemphasized. There is considerable evidence that failure to manage supply chain risks effectively can have a significant negative impact on organisations (Mitchell, 1995). According to Hendricks and Singhal (2005) in Khan and Burnes (2007), failure to manage supply chain risks can have multiple consequences such as bringing about a sharp downturn in an organisation's share price, and can also generate conflict amongst the organisation's stakeholders. Other wider consequences of failure to effectively manage risk have been identified by Cousins et al. (2004) and include financial losses, reduction in product quality, damage to property and equipment, loss of reputation in the eyes of customers, suppliers and the wider public, and delivery delays.

Incidents of Supply risk are not limited to any industry, country, region or continent. Over the past 18 months, the media in Malawi (a southern African country) was awash with reports on the worsening situation of drug shortage in the country's public hospitals (e.g. Mmana, 2011) despite the same being adequately available in private and Christian Health Association of Malawi (CHAM) hospitals. This raised questions regarding both internal and external forces (Day and Lichtenstein, 2006) affecting the ability of procurement functions at public hospitals to ensure availability of medicines in public hospitals. Such shortages / stock outs can have fatal consequences on 
patients because they can result in total failure of healthcare delivery systems (White and Mohdzain, 2009). With a single supplier, the supply risk at hospitals could be greater since all procuring entities would be prone to forces affecting the supplier (Khan and Burnes, 2007). This is in direct contrast with the CHAM hospitals which have multiple suppliers and continue to enjoy high levels of availability of medical supplies.

In the remainder of the paper we provide the problem statement and objectives of the study. This is followed by a literature review presented in three section overviews of Supply Chain Risk, Supply Chain Risk Management (SCRM), and Sourcing Strategy and Supply Risk. Next, the research methodology is presented before findings of the study are presented and discussed. The final section of the paper presents the conclusions, practical implications and limitations.

\subsection{Problem Statement and Objectives of the Study}

The status of availability of drugs and other essential medical supplies in Malawi's public Healthcare Delivery Supply Chain (PHDSC) has continued to deteriorate over the past 18 months. The situation has culminated into persistent stock outs of drugs in the PHDSC while private hospitals such as those under the Christian Health association of Malawi continue to enjoy adequate supply of drugs over the same period. In their study on the impact of procurement performance on healthcare delivery, Kanyoma and Khomba (2013) reveal that the stock outs have paralysed healthcare delivery systems and caused death of patients, delays in medical surgery, and worsened medical conditions of patients among other effects. This raises questions regarding both internal and external forces (Day and Lichtenstein, 2006) affecting the ability of procurement to ensure availability of medicines in public hospitals. One such a factor is sourcing strategy, which represent the main difference between the PHDSC and private hospitals which enjoy a healthy supply of drugs. On one hand, the former uses a single sourcing system, relying on a government instituted supplier namely the 'Central Medical Stores'; On the other hand, the latter have adopted a multiple sourcing strategy.

The study therefore sought to establish the relationship between the persistent stockouts of drugs in the PHDSC, and the sourcing strategy. While Khan and Burnes, (2007) have linked single sourcing to the risk of supply failure, this study sought to empirically investigate the existence of such a relationship. The research had the following 2 specific objectives: (i) to investigate whether single sourcing exacerbated or mitigated the risk of supply failure (stock outs) in the PHDSC. (ii) to investigate the role of the single supplier in exacerbating the risk of stock outs.

\section{Literature Review}

\subsection{Sourcing Strategy and Supply Chain Risk}

The issue of risk in supply chain is becoming more and more important for many reasons such as uncertainty in supply and demand (Christopher and Lee, 2004, Tang, 2006). Because of such growing importance of risk in supply chains, Micheli, Cagno and Zorzini, (2008) suggest that supply chain management must become oriented to supply chain risk management. Juttner, Peck, and Christopher, (2003, p.198) have defined supply chain risk as "the variation in the distribution of possible supply chain outcomes, their likelihoods, and their subjective values". Yu, Zeng and Zhao (2009) recommend an effective sourcing strategy to combat unreliable supply and stochastic demand in order to avert supply chain risk. In his abstract on sourcing for global health supply chains for developing countries, Pazirandeh, (2011) advises that supply base decisions must help the organization to 'improve availability, quality, innovation, and accessibility of the product in a more secure market at lower prices'. Extant literature further suggests a strong link between supply base and supply chain risk (Srinivasan, Mukherjee, and Gaur, 2011). The study of Sarkar and Mohapatra (2009) also links supply disruption risks with supply base size.

Yu et al. (2009) establish the link among three concepts namely sourcing strategies, supply base and supply risk. They argue that a single sourcing strategy, which represents the narrowest form of supply base and strives for a strategic partnership between a buyer and a supplier and also optimizes shared benefits, can be used to proactively cope with supply risks. However, Khan and Burnes (2007) is opposed to such a strategy arguing that single sourcing effectively puts all the eggs in one basket there by increasing the supply risk. Yu et al, (2009) note that many firms are now turning to multiple sourcing in order to spread the risk. In agreement, Hou, Zeng and Zhao (2010, p.881) observe that 'while suppliers play an important role in achieving the entire supply chain excellence, they also represent one major source of uncertainty and disruption'. They recommend that buyers should have more than one supplier to reduce the supply risk. Dependency of both partners on one another is cited as the one major drawback associated with single sourcing. According to Mustaffa and Potter (2009), resultant supply failure from such dependency can have fatal consequences in healthcare systems. This observation is also made by Yu et al. (2009), 
who also recognize a growing popularity of multiple sourcing among firms as a way of averting exposure to greater risks supply chain disruptions associated with the single sourcing.

Yu et al (2009) identify three approaches to sourcing namely; i) single sourcing, which they differentiate from sole sourcing as they observe that the latter refers to a buyer-supplier relationship where the supply base contains only one supplier, where as the former exists when a buyer chooses a single supplier even though other comparable suppliers do exist in the supplier base. Thus, single sourcing is a matter of choice; ii) dual sourcing, in which a buyer employs two suppliers, one of which may dominate the other in terms of business share, price, reliability, and others (see also Hou et al, 2010) and; iii) multiple sourcing, where a buyer does business with several suppliers and plays one supplier against the other to enjoy the best price advantage. They do not only contend that matters relating to the size of a firm's supply base are not always a question of choice, but also acknowledge that in some cases the supply base does not offer adequate options to buying firms in terms of both the number and capabilities of available suppliers.

The dangers of single sourcing in respect of consequent supply failure are highlighted clearly by Khan and Pillania (2008) in their abstract on supply chain agility and firms' performance. They note that supply chain nodes are prone to disruptions, bankruptcies, breakdowns, macroeconomic and political changes, and disasters leading to higher risks. This means single sourcing may represent the worst form of exposure to the risk of supply failure. In such scenarios, dual or multiple sourcing could hedge against supply failure (Khan and Burnes, 2007). Other authors contest that single sourcing is reactive rather than proactive and cannot mitigate supply chain risks (eg. Hou et. al, 2010; Burke, Carrillo, and Vakharia 2007). In this regard, Yu et al. (2009) reiterate that unless firms are able to find alternatives quickly for unexpected disruptions, supply chains will be susceptible to system shocks and disruptions. This implies the superiority of dual sourcing over single sourcing strategies.

The relevance of single sourcing is further highlighted by Burke, Carrillo, and Vakharia (2007), in their abstract titled 'single versus multiple supplier sourcing strategies', where they indicate that the former is an ideal strategy only when (i) supplier capacities are large relative to the product demand and (ii) when the buying firm does not obtain diversification benefits. They contend that with the exception of the above scenarios, dual sourcing is an optimal sourcing strategy in all other cases. Dependency of both partners on one another is cited as the one major drawback associated with single sourcing. According to Mustaffa and Potter (2009), resultant supply failure from such dependency can have fatal consequences in healthcare systems. This observation is also made by $\mathrm{Yu}$ et al. (2009), who also recognize a growing popularity of multiple sourcing among firms as a way of averting exposure to greater risks supply chain disruptions associated with the former strategy.

\subsection{Supply Chain Risk Management (SCRM)}

Christopher et al., (2003) define SCRM as, "the identification of potential sources of risk and implementation of appropriate strategies through a coordinated approach among supply chain members, to reduce supply chain vulnerability". Thus, from the definition it is clearly shown that in SCRM the emphasis is not on the individual organisation but on all players in the supply chain because as noted by Bakshi and Kleindorfer (2009), failure of any one node in the supply chain could imply a failure of the complete supply network. An increasing number of writers have sought to move the focus of attention away from analysing and managing risk at the level of individual customers and suppliers and towards the understanding and management of risk for the entire supply chain (Khan and Burnes, 2007; Cousins et al., 2004; Harland et al., 2003; Lewis, 2003). Other scholarly works have also focussed on the vulnerability of supply chains, other than individual organizations. For example, Wong, McFarlane, Zaharudin, and Agarwal (2002), as cited in Yu et al, (2009) have found that today's supply chains are built to be lean and efficient, but if they are unable to find alternatives quickly for unexpected disruptions, the chains will be susceptible to system shocks and disruptions. Many authors have emphasized the need to consider risks arising from network collaboration and interactions between supply chain partners (Blos et al., 2009; Kull and Talluri, 2008; Ritchie and Brindley, 2007; and Finch, 2004).

Cousins et al. (2004) identify two main types of supply chain risk to which companies can become exposed namely (i) technological risk - which comes from over-reliance on a single or limited source of a product, process, or technology; and (ii) strategic risk - arising from over-reliance on a single or limited number of suppliers. Strategic risk can be said to emanate from the supply base concept which relates to the number, range, location and characteristics of the vendors that supply the purchaser (Yu, et al. 2009). Cousins et al. (2004) also suggest that some of the measures which companies take to improve the efficiency of their supply base, such as de-listing under-performing suppliers, may increase their exposure to both technological and strategic risk by increasing their reliance on the remaining pool of suppliers (see also Khan and Barnes, 2008). The main challenge, as argued by 
Hendricks and Singhal (2005), is that in developing supply chain strategies which focus on cost reduction, organisations have ignored or played down the risks from supply chain disruptions.

Hendricks et al., (2009) posits that better understanding on the relationships between a set of strategies for managing supply risk and the impact on the performances would provide interesting insights in the field of SCRM. In particular, Wagner and Bode, (2008), provide a clear description of the role of SCRM strategies. They argue that SCRM strategies are justified only if supply chain risks interfere with companies' performances. Thus, according to Wagner and Bode, (2008), in the midst of numerous supply chain risks, firms should make an assessment and develop SCRM strategies with a focus on mostly those risks that can potentially affect organizational performance. On their part, Collichia \& Strozzi, (2011) propose four basic approaches to SCRM namely supply management, demand management, product management, and information management. Zsidisin \& Wagner, (2010) contends that while supply chains face a wide range of supply disruptions and/or risks, each risk or disruption might require a specific SCRM technique.

Regarding SCRM strategy choice, Fisher, (1997) advises that although supply chain risks can be reduced through improved processes and buffer strategies, organizations still need to take actions against unforeseen events because risk cannot be completely eliminated. While not disagreeing with the Fisher (1997), Kumar et al., (2008) emphasizes the role of buffer strategies especially in healthcare delivery systems where stock outs have fatal effects. However, Michelli et al., (2008) stress that for complex supplies in general, buffer strategies cannot be easily and economically implemented. This calls for organizations to make effort in implementing process improvement strategies to reduce the risk propensity, for example by forming strategic alliances and by developing suppliers as argued by Giunipero and Eltantawy, (2004).

Tomlin, (2009) proposes the use of two strategies namely dual sourcing and inventory in order to avert two kinds of supply chain risks namely supply disruptions and recurrent supply uncertainty. Hou et al (2009) describe supply disruption is the sudden stop of supply arising from unexpected events that result in the main source becoming totally unavailable. According to Ellis et al., (2010), supply disruption is an infrequent risk which tends to have large impacts on the whole supply chain, because it could cut off the cash flow and stop the operation of the entire supply chain. The effect of such supply disruption can be unimaginable in the case of healthcare systems under single sourcing. Hou et al., (2010) associate recurrent supply uncertainty with uncertain delivery volumes, which entails that the quantity delivered by the supplier is not the same as what is ordered by the buyer, even though the supplier is able to deliver the goods. Tomlin, (2009) refers to such uncertain delivery volumes as 'random yield' and suggests the use of dual sourcing and inventory in such situations.

There is wide consensus, both in the literature and in practice, that managing risk in the supply chain is a critical capability in order to compete in the current, increasingly turbulent and unpredictable, business environment (Collichia and Strozzi, 2011). The uncertainty of the business environment and the very complexity of supply chain networks appear to be increasing the probability of experiencing supply chain disruptions, (Bakshi and Kleindorfer, 2009; Chopra et al., 2007). Both academics and practitioners have begun to address "disruption management", in order to reduce the risk of disruptions, mitigate their negative impact on performance and restore the supply chain to normal operation as soon as possible (Adhitya et al., 2009; Hendricks et al., 2009; Lodree and Taskin, 2008). Collichia and Strozzi (2011, p412) identify two key challenges to developing an effective disruption management system namely: 'developing supply chain design models able to take into account the uncertainty and complexity in which supply chains operate; and developing structured and systematic tools for risk identification and assessment that explicitly consider the dynamic interactions among supply chain partners and among risk sources'. Adhitya et al., (2009), contend that these interactions are in fact, considered among others, as a source of disruptions.

As a risk management strategy, Scannell et al. (2013), recommend the adoption of Enterprise Risk Management (ERM) which is defined by Bowling and Rieger (2005) as a process for identifying, analyzing and proactively planning responses to a portfolio of risks. They (Scannell et al., 2013) observe that although ERM is not widely adopted, it provides a framework and set of tools for managing risks holistically. In their abstract, they (ibid) also provide an inventory of SCRM strategies which they refer to as 'treatment options' (Scanelli Et al., 2013. p.20) some of which are: evaluation and trust building; use of dual sources (see also Khan \& Burnes, 2007), buffer inventory (Tang, 2006), strategic sourcing and flexibility (Chiang et al., 2012), and supplier development (Matook et al., 2009); supply chain modeling and information systems integration (Giannakis \& Louis, 2001), Supplier qualification, and supplier quality management initiatives.

\section{Methodology}

\subsection{Data Collection}

The study collected data from two different categories of staff namely hospital managers / administrators, and procurement managers at five public healthcare delivery centres in Southern Malawi. A combination of quantitative 
and qualitative data collection instruments was used. This comprised questionnaires and interviews respectively. Data was collected through two sets of self completed questionnaires, which allowed respondents to complete at their convenience thereby minimising interruptions to healthcare delivery at participating hospitals. Follow up interviews with randomly selected managers were also conducted in order to obtain clarification on any ambiguous or contradicting results from the study. These interviews were semi-structured in order provide both in-depth and specific insight into the understanding, interpretation and discussion of findings (Black, 2005).

\subsection{Questionnaire Design}

The first questionnaire, completed by procurement staff, investigated the causes of stock outs at respective hospitals from the 'horse's mouth', and assessed the performance of the single supplier and how the same affected availability of medical supplies. The second questionnaire was completed by hospital managers and administrators. It probed into the effects of procurement in healthcare delivery; and the role of sourcing strategy in improving responsiveness and averting supply risks respectively. Although the two questionnaires mostly addressed similar issues, the responses from the different respondent categories helped illuminate different aspects of the research problem according to Gill and Johnson, (2006). Although the research was generally qualitative, questionnaires were quantitatively designed to increase objectivity. A five point Likert Scale was used with response options ranging from 'strongly disagree', 'disagree', 'neutral', or 'do not know' (as the case may be), 'agree', to 'strongly agree'. Open ended questions were also included to allow for the collection of in depth data.

\subsection{Sampling}

A total 40 questionnaires were sent out from which 34 questionnaires were collected representing an overall response rate of $85 \%$. Among hospital managers, 35 questionnaires were sent and 29 collected representing a response rate of $82.9 \%$. 5 questionnaires were distributed to procurement managers for respective hospital all of which were collected representing a $100 \%$ response rate. Stratified random sampling which involves taking a random sample from identifiable groups (strata) that are homogenous for the desired characteristics' (Black, 2005), such as people working in one hospital ward or belonging to the same profession, was used to distribute questionnaires to hospital managers. For procurement staff, non-probabilistic purposive sampling which involves handpicking respondents based on desired traits (Black, 2005) was used to ensure that only functional heads participated.

\subsection{Data Analysis}

Quantitative data was analyzed using Statistical Packages for Social Sciences (SPSS) whereas thematic analysis (Braun, 2006) was adopted for qualitative data. Themes were identified in textual data based on three criteria namely recurrence, repetition and forcefulness (Keyton, 2006).

\section{Results and Discussion of Research Findings}

This section discusses results concerning the main research question on the role of single sourcing in either exacerbating or mitigating supply risks in Malawi's public healthcare supply chain. Regardless of the other causes that were cited in this and other studies, the majority of respondents comprising procurement staff and hospital managers / administrators at all hospitals agreed that persistent stock outs of drugs largely arose from factors related to the behaviour, failures or the mere existence of a single supplier namely the Central Medical Stores.

\subsection{Single Sourcing as a Cause of Stockouts}

A wide range of factors were appraised regarding their contribution to the persistent stockouts and the results apportioned the blame mostly to three causes namely: delays by procurement staff, withholding of funds by donors, and insufficient inventory at the Central Medical Stores (CMS), a government instituted single supplier of drugs to public hospitals. The inclusion of CMS among the causes of stock outs does not only speak volumes about the performance of the single supplier, but also greatly underscores the risk associated with the single sourcing strategy since supplier underperformance, howsoever caused, potentially culminated into supply failure. Discussed hereunder are the causes of stockouts in the PHDSC in rank order of significance based on statistical mean values presented in Table 1 below.

\subsubsection{Insufficient Inventory at CMS - The Main Cause of Stockouts}

Of the three major causes of stock outs cited in the study, insufficient inventory at the CMS ranked highest followed by delays by procurement staff and the withholding of fund (meant for the procurement of drugs for the CMS) by donors. $76.5 \%$ of all respondents either agreed or strongly agreed that insufficient inventory at the single supplier caused stock outs. This is opposed to $14.7 \%$ of respondents that lacked knowledge on the matter, whereas the remaining $8.8 \%$ disagreed. In the summary of results presented in Table 1 below, insufficient inventory the highest 
mean value at 4.1. The high mean value is an important indicator of the significance of this factor in strategy formulation. The overwhelming level of agreement among respondents, who are generally well informed about the frequency, effects, and causes of stock outs, validates not only the significance of sourcing strategies in exacerbating the stock outs in PHDSC, but also the role of the single supplier in exacerbating the crisis / stockouts. The results could not in any way be just a matter of opinion on the part of the respondents given that $82.8 \%$ of the managers in the study were members of the internal procurement committee (IPC) at their respective hospitals while 100 percent of the procurement managers (purposively sampled) were also IPC members.

\subsubsection{Withholding of Funds by Donors}

There is a big contrast in the rankings between the role of the single supplier (the CMS) and that of the donors in causing the stockouts. In responding to the question on whether the withholding of funds by Health Sector-wide Approach (HSwAp) donor partners contributed to or caused stockouts in respective public health facilities, 29.4\% and $17.6 \%$ of respondents agreed and strongly agreed respectively, that the HSwAp donor partners significantly contributed to the recurrent stockouts. This represents a combined $47 \%$ of all respondents. While $23.5 \%$ expressed lack of knowledge on the matter, the remaining $29.4 \%$ either disagreed or strongly disagreed. Although the behaviour of the donors in withholding funds can be treated as a standalone contributory factor to the recurrent stockouts, there is a more direct link between this factor and the failure of the single supplier to hold sufficient inventory. Because the CMS relies on both government and HSwAp donor funds for its operations, any delay or failure by either source of funds could affect the supplier's ability to adequately stock up. However, the question is not whether the blame could be placed on the donor partners or the single supplier. Of paramount significance is the revelation that in the face of failure by the single supplier to ensure availability of drugs, there were no alternative sources of drugs available to public health facilities. The relevance of single sourcing, therefore, comes into question.

\subsubsection{Delays by Procurement Staff}

On this third suspect factor, a combined $50 \%$ of respondents (strongly) agreed that stock outs arose from delays by procurement staff with $26.5 \%$ agreeing and $23.5 \%$ strongly agreeing. Of the remaining half of respondents, $11.8 \%$ did not know about the relationship between delays in procurement and stock outs, while a combined $48.2 \%$ disagreed. These results vindicate the fact that medical supplies were mostly unavailable on demand. The study further reveals that there were delays by the supplier in communicating its inability to meet an order to respective procuring units at public healthcare facilities. Thus, while this result is statistically valid, there is a real need to delve into the reasons behind the delays by procurement staff. Nevertheless, although delays in procurement are a significant factor in any efforts to avert the supply failure in public hospitals, the use of single sourcing remains the single most important cause of the stockouts. This argument is strongly supported by other results on the role of CMS in the crisis as discussed in the next section.

\subsection{4 'Wrong Demand Forecasting' and 'Unexpected Disease Outbreaks'}

Inability to accurately forecast demand for various medical supplies was also probed into as a potential cause of recurrent stockouts. On the ranking scales, a 73.5\% majority of respondents (strongly) disagreed that stock outs arose from wrong demand forecasting, compared to only $20.6 \%$ that (strongly) agreed and the remaining $5.9 \%$ that did not know. Another potential factor closely related to demand forecasting is the occurrence of emergencies such as unexpected disease outbreaks. Results indicate that emergencies were not among the important causes of the crisis given that a combined $56.2 \%$ of respondents (strongly) disagreed as opposed to a combined $28.2 \%$ that (strongly) agreed that unexpected disease outbreaks caused the stockouts. $15.6 \%$ of respondents lacked knowledge on the matter. These results confirm that stockouts neither emanated from failure to accurately forecast the demand levels nor from emergencies such as unexpected disease outbreaks. This revelation entails that policy makers have to first look elsewhere in their attempts to arrest the situation.

\subsubsection{Lack of Funds at Hospital Level}

Many other factors were also rated on their contributory effect to the stock outs in Malawi's PHDSC as summarised in Table 1 below. On lack of funds at respective hospitals being one of the causes of stock outs, a combined $23.6 \%$ of respondents agreed or strongly agreed as opposed to a combined $61.7 \%$ that either disagreed or strongly disagreed. The remaining $14.7 \%$ lacked knowledge on the matter. This was no surprise result given that hospitals were adequately funded 2011 / 2012 Government of Malawi fiscal year (Malawi National Budget, 2011). The stock outs arose because the CMS ran out of drugs and in most of the cases resorted to rationing the available supplies to the public hospitals. This is a case of random yield, a well known challenge associated with single sourcing, in which the 
supplier only delivers a random portion to the customer thereby potentially creating the possibility of supply failure (Tomlin, 2009).

\subsubsection{Poor Inventory Management}

Poor inventory management was the second least important cause of stockouts according to mean values in the statistical summary of results. On the ranking scales, a combined $64.7 \%$ of respondents disagreed, compared to $17.7 \%$ who either agreed or strongly agreed that poor inventory management in the pharmacies of respective hospitals was responsible for the stockouts. $17.6 \%$ did not know about the existence of such a relationship. One challenges facing pharmaceutical staff is that of avoiding expiry of drugs by putting in place inventory management systems that ensure stocks do not expire before being used. Despite the fact that this study confirmed that all participating hospitals had registered cases of drugs being disposed off due to expiry within the previous two years, there is no evidence linking the expiry and eventual disposal of drugs to the persistent stockouts. As a matter of fact, expiry of drugs was found to originate from the dumping of drugs by various donor organisations into public hospitals when such drugs were already nearing expiry. In this regard, poor inventory management cannot be considered to be significant in searching for solutions.

\subsubsection{Unavailability of Drugs on the Market}

Another prime suspect for the existence of stock outs could be unavailability of drugs on the market. This factor registered the highest rejection rate with $86.2 \%$ of respondents disagreeing, $10.8 \%$ indicating lack of knowledge whereas only $3 \%$ agreed. This factor also registered the lowest mean value of 1.7. The result is suggestive of the reality concerning the availability of drugs on the market during the period of the study. At the time when public hospitals were languishing with stockouts, private hospitals continued to enjoy adequate supplies of drugs. It was for this reason that there was a general exodus of patients from the latter to the former (see also Kanyoma and Khomba, 2013). The key distinction between the public and private hospitals is that the latter do not procure their supplies from the CMS, and are not in any way locked up in any single sourcing relationship, while the latter can only get their supplies from the government instituted single supplier, except in such cases special permission has been granted by the same supplier (CMS) allowing them to buy drugs from other sources. Moreover, the fact that the crisis occurred when public hospitals had sufficient funds for the procurement of drugs, proves the existence of challenges concerning the supplier and /or the sourcing strategy.

The following are the causes of stock outs of drugs at our hospital:

Table 1. Statistical summary of research findings on causes of stockouts in hospitals

\begin{tabular}{lccccccc}
\hline & $\begin{array}{l}\text { Strongly } \\
\text { disagree }\end{array}$ & Disagree & $\begin{array}{l}\text { Don't } \\
\text { know }\end{array}$ & Agree & $\begin{array}{l}\text { Strongly } \\
\text { agree }\end{array}$ & Total & Mean \\
\hline $\begin{array}{l}\text { i) Insufficient Inventory at } \\
\begin{array}{l}\text { Central Medical Stores } \\
\text { (CMS) }\end{array}\end{array}$ & $5.9 \%$ & $2.9 \%$ & $14.7 \%$ & $32.3 \%$ & $44.2 \%$ & $100 \%$ & 4.1 \\
$\begin{array}{l}\text { ii. Withholding of funds by } \\
\text { donor partners }\end{array}$ & $08.8 \%$ & $20.6 \%$ & $23.5 \%$ & $17.6 \%$ & $29.5 \%$ & $100 \%$ & 3.4 \\
$\begin{array}{l}\text { iii.)Delays by procurement } \\
\text { staff }\end{array}$ & $17.6 \%$ & $20.6 \%$ & $11.8 \%$ & $26.5 \%$ & $23.5 \%$ & $100 \%$ & 3.2 \\
$\begin{array}{l}\text { iv)Wrong } \\
\text { forecasting }\end{array}$ & $41.2 \%$ & $32.3 \%$ & $5.9 \%$ & $8.8 \%$ & $11.8 \%$ & $100 \%$ & 2.8 \\
$\begin{array}{l}\text { v) Unexpected disease } \\
\text { outbreaks } \\
\text { vi) Lack of funds at the }\end{array}$ & $21.8 \%$ & $34.4 \%$ & $15.6 \%$ & $18.8 \%$ & $09.4 \%$ & $100 \%$ & 2.6 \\
$\begin{array}{l}\text { hospital } \\
\text { vii)Poor inventory } \\
\text { management by } \\
\text { pharmacies } \\
\text { viii) Unavailability of }\end{array}$ & $29.4 \%$ & $32.3 \%$ & $14.7 \%$ & $17.6 \%$ & $5.9 \%$ & $100 \%$ & 2.4 \\
drugs on the market & $20.6 \%$ & $44.1 \%$ & $17.6 \%$ & $5.9 \%$ & $11.8 \%$ & $100 \%$ & 2.4 \\
\hline
\end{tabular}




\subsection{Supplier Performance and Supply Risk under Single Sourcing Conditions}

Whereas the relationship between supplier performance and supply risk or supply failure is most of the times speculated, results from this study do confirm that such a relationship is a more direct and certain under single sourcing conditions. The fact that buying organisations have no alternative sources of supply in cases of disruptions or disasters affecting the supplier makes the former more prone to supply failure. This is synonymous to putting all eggs in one basket as argued by Khan and Barnes, (2009). In this study, respondents were required to rate various aspects of the performance of the single supplier and how the same affected the availability of supplies at respective hospitals.

\subsubsection{CMS as the Main Cause of Stockouts of Drugs at Public Hospitals}

Opinions were sought from respondents on whether the CMS as a single supplier, could be as said to be the main cause in the persistent stock outs of drugs. $73.5 \%$ of respondents agreed as opposed to $17.6 \%$ that were neutral and $8.8 \%$ disagreed that CMS was the main cause of stock outs. The results are representative of the actual situation on the role of the CMS in the persistent stock outs. The study further revealed that the CMS represented the single most important bottleneck in the public healthcare delivery supply chain, which many a time almost brought the entire PHDSC to a halt due to failure to ensure availability of key medical supplies. As revealed in the study, the CMS did not only exacerbate the risk of supply failure at public hospitals through their own frequent stock outs, but also through delays in communicating to respective hospitals about their (CMS') inability to meet specific orders.

Further challenges come from failure by CMS in issuing clearances that allow hospitals procure the drugs from private suppliers. Such delays resulted in a situation where public hospitals run out of stock of some types of drugs. Thus, the single supplier can in this respect, be held responsible for the stock outs. It is therefore not surprising that $73.5 \%$ of respondents indicated agreement to suggestions that the CMS caused delays in the procurement of drugs at respective hospitals. This result implies that any attempts to ensuring availability of key medical supplies at public hospitals should include efforts to improving effectiveness of the CMS and / or widening the supply base. While it can be said that a different single supplier could perform better than the CMS, it is still apparent that the mere use of a single source exposes buyers to a greater risk by subjecting them to any sources of supply disruptions affecting the supplier. In other words, it can be argued that the situation would be different if dual or multiple sourcing were used in Malawi's PHDSC since failure by one supplier could be made up for by another.

\subsubsection{CMS Frequently Runs out of Drugs}

The inadequacy of single sourcing for the PHDSC in Malawi has been more clearly pronounced by the inability of the CMS to maintain a sufficient inventory of drugs that is required to meet demand at respective hospitals. The results indicate an unusually high level of supplier underperformance that cannot be expected to come from a single supplier. Such supplier underperformance suggests lack of supplier capacity to meet customer demand, and endorses assertions by Burke, Carrillo, and Vakharia (2007), who contend that single sourcing is an ideal strategy only when supplier capacities are large relative to the product demand. In confirming the frequency of stock outs at the CMS, which culminates into stockouts at hospitals, $67.6 \%$ and $22.6 \%$ of respondents agreed and disagreed respectively that the supplier frequently ran out of drugs. The other $11.8 \%$ remained neutral. These results are supported by both revelations about the existence of random yield in the PHDSC; and the high supplier delivery failure rate which stood at an average of $35 \%$, as rated by procurement officers in the study.

For any system and by all standards, such a delivery failure rate by a supplier can be considered too high. The case in point is worse considering the nature of healthcare delivery and the implications of supply failure in such a system. Mustaffa and Porter (2009) strongly advise hospital managers to ensure availability of adequate inventory at all times because failure to do so has serious consequences the worst of which being loss of life. Nevertheless, high levels of supply delivery failure are tolerable when organizations adopt dual or multiple sourcing strategies since, as Khan and Pillania, (2009) contend, it is less probable that two or three suppliers will fail to deliver at the same time. Dual or multiple sourcing strategies would in that respect, reduce the risk of supply failure in Malawi's PHDSC.

\subsubsection{CMS Reduces Variety of Drugs Available to Public Hospitals}

The results also suggest that the CMS was also responsible for the declining variety of drugs available at public hospitals. This is strongly supported with the evidence about frequent of stock outs as well as the high supplier failure rate of $35 \%$ discussed above. The declining variety of drugs has been discovered to be one of the major factors affecting healthcare delivery in the PHDSC. The study has revealed that non-availability of certain types of drugs, and the existence of a generally narrow range of inventory of medical supplies does not only affect the supply 
chain's downstream customer, but also demotivates doctors in giving prescriptions of drugs which despite being essential, are not available'. Such a situation is risky considering the nature of healthcare delivery.

The results may not represent the situation in all single sourcing systems within and outside healthcare supply chain management systems across the globe. Nevertheless, the results are highly generalizable in that they do point out one important aspect regarding the dangers of single sourcing strategies. This argument is vindicated by Khan and Pillania, (2008), who contend that single sourcing may represent the worst form of exposure to the risk of supply failure. The challenge revealed in this study was bigger since hospitals were never allowed to buy from private suppliers unless they received clearance from the single supplier.

\section{Conclusion and Recommendations}

The research has confirmed findings from previous studies (eg. Srinivasan, Mukherjee, and Gaur, 2011; Khan and Burnes, 2009; Yu, Zeng and Zhao, 2009; Khan and Pillania, 2008) regarding the role of sourcing strategy in managing supply risk. It empirically establishes that single sourcing strategies exacerbate the risk of supply failure. It has also shown that supply failure in healthcare delivery systems can have fatal consequences such as deaths of patients. Thus, from the research, new knowledge to policy makers is created namely that, all things being equal, 'single sourcing strategies are not appropriate for healthcare delivery systems'. Based on the foregoing, dual or multiple sourcing strategies are recommended because they are an effective means of hedging against the risk of supply failure since non-delivery by one supplier is covered by another. Thus, availability of medical supplies in hospitals would be safeguarded because the effects of supply disruptions affecting one supplier would no longer result in total supply failure for buying organization.

The major limitation of the study is that it was conducted at a time when stock outs of drugs were at crisis levels in Malawi's public hospitals. The results may therefore strongly represent the situation at that material point in time, other than the status under normal conditions of supply.

\section{References}

Aronsson, H., Abrahamsson, M., \& Spens, K. (2011). Developing lean and agile health care supply chains. Supply Chain Management: An International Journal, 16(3).

Bakshi, N., \& Kleindorfer, P. (2009). Co-operation and investment for supply-chain resilience. Production and Operations Management, 18(6), 583-603. http://dx.doi.org/10.1111/j.1937-5956.2009.01031.x

Black, T. R. (2005). Doing Quantitative Research in the Social Sciences: an Integrated Approach to Research Design, Measurement and Statistics. London: Sage Publications

Burke, G.J., Carrillo, J.E., \& Vakharia, A.J. (2007). Single versus multiple supplier sourcing strategies. European Journal of Operational Research, 182(1), 95-112. http://dx.doi.org/10.1016/j.ejor.2006.07.007

Chandra, C., Kumar, S., \& Ghildayal, N.S. (2009). Hospital cost structure in the USA: what's behind the costs? A business case. International Journal of Health Care Quality Assurance, 24(4), 314-328. http://dx.doi.org/10.1108/09526861111125624

Chopra S, Reinhardt G, \& Mohan U. (2005). The importance of decoupling recurrent and disruption risks in a supply chain. Working paper, North Western University.

Collichia, C., \& Strozzi, F. (2012). Supply chain risk management: a new methodology for a systematic literature review. Supply Chain Management: An International Journal, 17/4(2012), 403-41. Emerald Group Publishing Limited. http://dx.doi.org/10.1108/13598541211246558

Faes, W., \& Matthyssens, P. (2009). Insights into the process of changing sourcing strategies. Journal of Business \& Industrial Marketing, 24(3), 245-255. http://dx.doi.org/10.1108/08858620910939796

Hendricks, K.B., Singhal, V.R., \& Zhang, R.R. (2009). The effect of operational slack, diversification, and vertical relatedness on the stock market reaction to supply chain disruptions. Journal of Operations Management, 27(3), 233-46. http://dx.doi.org/10.1016/j.jom.2008.09.001

Hou, J., Zeng, A, Z., \& Zhao, L. (2010). Coordination with a backup supplier through buy-back contract under supply disruption. Transportation Research Part E, 46, 881-895.

Juha, M., \& Pentti, J. (2008). Managing risks in Organisational purchasing through adaptation of buying centre structure and buying process. Journal of Purchasing and Supply Management, 14, 253-262. http://dx.doi.org/10.1016/j.pursup.2008.09.001 
Juttner, U., Peck, H., \& Christopher, M. (2003). Supply chain risk management: outlining an agenda for future research. International Journal of Logistics: Research and Applications, 6(4), 197-210. http://dx.doi.org/10.1080/13675560310001627016

Kanyoma, K. E., \& Khomba, J.K. (2013). The Impact of procurement operations on healthcare delivery: a case study of Malawi's Public Healthcare Delivery system. Global Journal of Business and Management Research.

Karjalainen, K. (2010). Estimating the cost effects of purchasing centralization - Empirical evidence from framework agreements in the public sector. Journal of Purchasing and supply Management, 17, 87-97. http://dx.doi.org/10.1016/j.pursup.2010.09.001

Khan, A. K., \& Pillania, R.K. (2008). Strategic sourcing for supply chain agility and firms' performance: A study of Indian manufacturing sector. Management Decision, 46(10), 1508-1530. http://dx.doi.org/10.1108/00251740810920010

Khan, O., \& Burnes, B. (2007). Risk and supply chain management: creating a research agenda. The International Journal of Logistics Management, 18(2), 197-216. http://dx.doi.org/10.1108/09574090710816931

Kleindorfer P.R, \& Saad G.H. (2005). Managing disruption risks in supply chains. International Journal of Production and Operations Management, 14(1), 53-68.

Kumar, A., Ozdamar, L., \& Zhang, C. N. (2008). Supply chain redesign in the healthcare industry of Singapore. Supply Chain Management: An International Journal, 13(2) 95-103. http://dx.doi.org/10.1108/13598540810860930

Kumar, S., DeGroot, R. A., \& Choe, D. (2008). The impact of package design within US hospital supply chain. International Journal of Physical Distribution \& Logistics Management, 38(8), 601-615. http://dx.doi.org/10.1108/09600030810915134

Lindgreen, A., Revesz, B., \& Glynn, M. (2009). Purchasing organization involvement in risk assessments, contingency plans, and risk management: an exploratory study: Guest editorial Purchasing orientation. Journal of Business \& Industrial Marketing, 24(3), 148-153. http://dx.doi.org/10.1108/08858620910939697

Meehan, J., \& Wright, G. H. (2010). Power priorities: A buyer-seller comparison of areas of influence. Journal of Purchasing \& Supply Management, 17, 32-41. http://dx.doi.org/10.1016/j.pursup.2010.05.002

Micheli, G.J.L., Cagno., E., \& Zorzini, M. (2008). Supply risk management vs supplier selection to manage the supply risk in the EPC supply chain. Management Research News, 31(11), 846-866. Emerald Group Publishing Limited. http://dx.doi.org/10.1108/01409170810913042

Miocevic, D. (2011, October 22). Organizational buying effectiveness in supply chain context: Conceptualization and empirical assessment. Journal of Purchasing \& Supply Management.

Mmana, D. (2011). We reveal what has caused this drug shortage: donors refuse to buy drugs after K2.5 billion irregularities in procurement. Weekend Nation, 15(44), Saturday, pp. 1-3. Retrieved from www.mwnation.com

Munson, C.L., \& Hub, J. (2009). Applications of O.R. Incorporating quantity discounts and their inventory impacts into the centralized purchasing decision. European Journal of Operational Research, 581-592.

Murray, J.G., Rentell, P.G., \& Geere, D. (2008). Procurement as a shared service in English local government. International Journal of Public Sector Management, 21(5), 540-555. http://dx.doi.org/10.1108/09513550810885822

Mustaffa, N.H., \& Potter, A. (2009). Healthcare supply chain management in Malaysia: a case study. Supply Chain Management: An International Journal, 14(3), 234-243. http://dx.doi.org/10.1108/13598540910954575

Pazirandeh, A. (2011). Sourcing in global health supply chains for developing countries: Literature review and a decision making framework. International Journal of Physical Distribution \& Logistics Management, 41(4), 364-384. http://dx.doi.org/10.1108/09600031111131931

Pohl, M., \& Forstl, K.. (2011). Achieving purchasing competence through purchasing performance measurement system design - A multiple-case study analysis. Journal of Purchasing \& Supply Management.

Scannell, V., Curkovic, S., Wagner, B.J., \& Vitek, M.J. (2013). Supply Chain Risk Management within the Context of COSO's Enterprise Risk Management Framework. Journal of Business Administration Research, 2(1). 
Srinivasan, M., Mukherjee, D., \& Gaur, A.S. (2011). Buyer-supplier partnership quality and supply chain performance: Moderating role of risks, and environmental uncertainty. European Management Journal, 29, 260-271. http://dx.doi.org/10.1016/j.emj.2011.02.004

Tang, C.S. (2006). Perspectives in supply chain risk management. International Journal of Production Economics, 103(2), 451-88. http://dx.doi.org/10.1016/j.ijpe.2005.12.006

Tomlin, B. (2009, Spring). Impact of Supply Learning When Suppliers Are Unreliable. Manufacturing \& Service Operations Management, 11(2), 192-209.

Trautmann, G., Bals, L., \& Hartmann, E. (2009a). Global sourcing in integrated network structures: the case of hybrid purchasing organizations. Journal of International Management, 15(2), 194-208. http://dx.doi.org/10.1016/j.intman.2008.09.001

Trautmann, G., Turkulainen, V., Hartmann,E., \& Bals, L. (2009b). Integration in the global sourcing organization: an information processing perspective. Journal of Supply Chain Management, 45(2), 57-74. http://dx.doi.org/10.1111/j.1745-493X.2009.03163.x

Van Weele, A.J. (2010). Purchasing and Supply Chain Management: Analysis, Strategy, Planning and Practice. Florence, KY: Cengage Learning Services.

White, A., \& Mohdzain, M. (2009). An innovative model of supply chain management: a single case study in the electronic sector. International Journal of Information Technology and Management, 8(1), 69-84. http://dx.doi.org/10.1504/IJITM.2009.022271

Yu, H., Zeng, A.Z., \& Zhao, L. (2009). Single or dual sourcing: decision-making in the presence of supply chain disruption risks. Omega - The International Journal of Management Science, 37, 788-800. http://dx.doi.org/10.1016/j.omega.2008.05.006 